\title{
Implementasi Metode Savi Untuk Meningkatkan \\ Motivasi Belajar Siswa Mojoagung Jombang
}

\section{IMPLEMENTASI METODE SAVI \\ UNTUK MENINGKATKAN MOTIVASI BELAJAR SISWA \\ MOJOAGUNG JOMBANG}

\author{
Ali Muhsin \\ Program Studi Pendidikan Agama Islam, Fakultas Agama Islam, Universitas \\ Pesantren Tinggi Darul Ulum Jombang \\ alimuhsin@fai.unipdu.ac.id
}

\begin{abstract}
Quality learning processes involve many things, one of which is the method or model applied by the teacher. If a teacher conveys varied and stimulating learning, students will be more interested in listening to the material presented. Conversely, if the teacher only teaches with conventional methods, namely lectures, students will be bored and not interested in listening to the material being taught. In this case the role of the learning method is very important to increase students' learning motivation, especially in the XI IPA class students.Assulaimaniyah whose application of learning is still a conventional method. They need varied learning not monotonous in order to support maximum learning outcomes, as well as the Application of SAVI Learning Methods to Increase Learning Motivation Sisawa Class XI Science MA.Assulaimaniyah Mojoagung Jombang. Based on this background, this study aims to conduct and determine the application of SAVI learning methods to improve student learning motivation when applied in the XI IPA MA class. Assulaimaniyah. Type of qualitative research with methods of collecting data on observation, interviews, documentation and library data. Data Analysis Techniques Data collection as well as data reduction, data presentation, verification and conclusions. The results showed that when the application of the SAVI method was applied, students who were previously lacking in enthusiasm in receiving learning were more enthusiastic and active in participating in these varied learning methods, so students could learn more optimally in learning. Supporting factors, positive support and encouragement from homeroom teacher and researcher motivation. Inhibiting factors Factors of oneself, such as lack of enthusiasm and enthusiasm that arise from them selves.
\end{abstract}

Keywords : Application of the SAVI Method, Increasing learning Motivation.

\section{A. PENDAHULUAN}


Proses pembelajaran yang berkualitas melibatkan banyak hal, salah satunya adalah metode atau model yang diterapkan oleh guru. Menurut slameto metode mengajar adalah salah satu cara atau jalan yang harus dilalui didalam mengajar. Metode pembelajaran yang diterapkan akan sangat mempengaruhi siswa dalam menyerap materi pembelajaran yang disampaikan oleh guru. ${ }^{1}$ Jika seorang guru menyampaikan pembelajaran yanga variatif dan menyenangkan, maka siswa akan lebih tertarik untuk menyimak materi yang disampaikan. Melalui Metode pembelajaran yang variatif dari guru, siswa memiliki kesempatan untuk membangun ide-ide baru dan menerapkan ide-ide tersebut dalam pembelajaran. ${ }^{2}$

Salah satu upaya untuk mengatasi rasa bosan dan dan memberi kesempatan pada siswa untuk lebih aktif adalah dengan menggunakan berbagai pendekatan dan salah satunya adalah SAVI ( Somatis, Audiotori, Visual, Intelektual ). Pendekatan SAVI merupakan pendekatan pembelajaran yang menggabungkan gerakan fisik dengan aktifitas intelektual siswa. Sedangkan unsur-unsur dari SAVI tersebut anatara lain adalah somatis yang merupakan belajar dengan bergerak dan berbuat, Audiotori merupakan belajar dan berbicara

\footnotetext{
${ }^{1}$ Irsa Ning Fitri dkk. , Efektivitas Metode Pembelajaran Snowball Throwing Pada Mata Pelajaran Al-Qur'an Hadist untuk Meningkatkan Minat Belajar Siswa Kelas XI di MAN 1 Jombang, Jurnal At-Tuhfah: Jurnal Studi Keislaman. Vol.8, No.2, 2019. h 30.

2 Emi Lilawati dan Hidayatur Rohmah, TANGGAPAN SISWA SMA KELAS X TERHADAP PEMBELAJARAN FIQIHBERBASIS MURDER (Studi kasus di SMA Darul Ulum 1 Unggulan BPPT Jombang), E- Prossiding SNAMI, 26 Oktober 2019, Vol 2 No 1 (2019). h 106.
} 


\section{Implementasi Metode Savi Untuk Meningkatkan \\ Motivasi Belajar Siswa Mojoagung Jombang}

serta mendengar, Visual belajar dengan mengamati, dan Intelektual adalah belajar dengan memecahkan masalah dan berfikir.

\section{B. METODE PENELITIAN}

Desain penelitian ini menggunakan penelitian Classroom Action Research atau Penelitian Tindakan Kelas (PTK). PTK adalah suatu pencermatan terhadap kegiatan yang sengaja dimunculkan dan terjadi dalam sebuah kelas.3 Pendekatan penelitian yang digunakan dalam penelitian ini adalah deskriptif kualitatif. Model yang digunakan dalam penelitian ini adalah model Kemmis dan Mc Taggart, yang mengembangkan model Kurt Lewin. Adapun siklusnya, yaitu:4

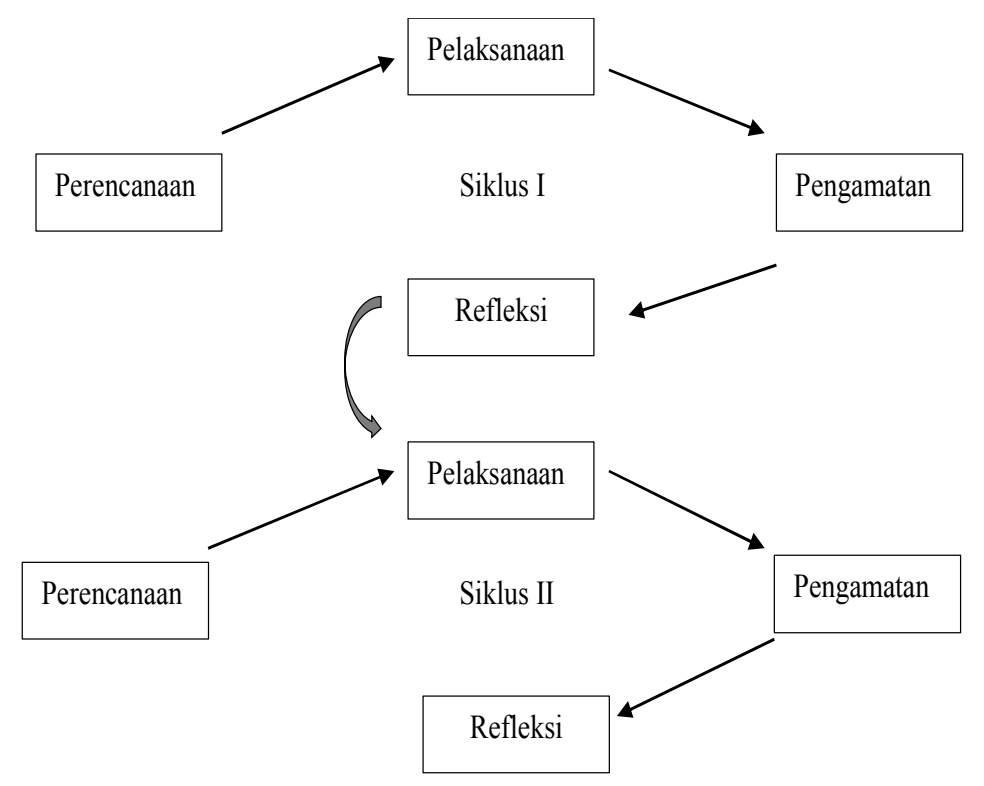

Gambar 2

Siklus PTK

\footnotetext{
${ }^{3}$ Suharsimi Arikunto, Prosedur Penelitian Suatu Pendekatan Praktik (Jakarta: PT Rineka Cipta, 2010), h. 130.
}

${ }^{4}$ Suharsimi Arikunto, dkk, Penelitian Tindakan Kelas (Jakarta: PT Bumi Aksara, 2014), h. 17. 


\section{Ali Muhsin}

Teknik pengumpulan data merupakan langkah yang paling utama dalam penelitian, karena tujuan utama dari penelitian adalah mendapatkan data. Adapun metode pengumpulan data yang penulis gunakan adalah sebagai berikut:

\section{Observasi}

Suatu metode pengumpulan data dimana peneliti mencatat setiap informasi sesuai dengan kenyataan yang mereka alami selama penelitian berlangsung. Pengalaman peneliti tersebut dapat terjadi berdasarkan melihat, mendengar dan meraskan dan kemudian dilaporkan sesubjektif mungkin. ${ }^{5}$

2. Metode Interview atau Wawancara

Wawancara adalah proses memperoleh keterangan untuk tujuan penelitian dengan cara tanya jawab sambil bertatap muka antara pewawancara dengan responden dengan menggunakan alat yang dinamakan interview guide (panduan wawancara). ${ }^{6}$

Metode wawancara dilakukan guna untuk menggali informasi tentang aktivitas guru dalam mengajar dan masalah yang dialami peserta didik. Dalam pengumpulan data peneliti secara langsung dan terbuka melakukan wawancara terhadap guru wali kelas dan siswa.

\section{Tes}

\footnotetext{
${ }^{5}$ Danang Sunyoto, Metode dan Instrumen Penelitian (Yogyakarta: PT Buku Seru, 2013), 64.

${ }^{6}$ Moh. Nazir, Metode Penelitian (Surabaya: Ghalia Indonesia, 2014 ), hal. 113.
} 


\section{Implementasi Metode Savi Untuk Meningkatkan \\ Motivasi Belajar Siswa Mojoagung Jombang}

Tes adalah suatu alat yang didalamnya berisi seumlah pertanyaan yang harus dijawab atau perintah-perintah yang harus dikerjkan, untuk mendapatkan gambaran tentang kejiwaan seseorang atau kelompok orang. ${ }^{7}$

\section{Angket}

Suatu metode pengumpulan data kualitatif yang bersifat koesioner yaitu seperangkat pertanyaan untuk mengungkapkan suatu informasiyang dibutuhkan dalam penelitian yang dimiliki oleh responden ${ }^{8}$

Teknis analisis data model interaktif dalam penelitian ini dijelaskan sebagaimana langkah-langkah berikut:

1. Reduksi data

Mereduksi data berarti merangkum, memilih hal-hal yang pokok, memfokuskan pada hal-hal yang penting, dicaritema dan polanya dan membuang yang tidak perlu. Dengan demikian data yang direduksi akan memberikan gambaran yang jelas, dan mempermudah peneliti untuk melakukan pengumpulan data selanjutnya.

2. Penyajian data

Setelah direduksi maka langkah selanjutnya adalah mendisplay data. Dalam penelitian kualitatif, penyajian data bisa dilakukan dalam bentuk uraian singkat, bagan, hubungan antar kategori, flowchart dan sejenisnya.

\footnotetext{
${ }^{7}$ Diyah Qurrota A'yuni, Efektivitas Penerapan Kolaborasi Pendekatan SAVI (Somatic Auditory Visualization Intelektually) Dan Pendektan Talking Stick Terhadap Hasil Belajar Peserta Didik Kelas VII Pada Materi Segiempat Di MTs. NU Hasyim Asy'Ari (Skripsi, UIN Walisongo Semarang,2015), h. 50.

${ }^{8}$ Ibid
} 


\section{Ali Muhsin}

Dalam hal ini Miles and Huberman, yang paling sering digunakan untuk menyajikan data dalam penelitian kualitatif adalah dengan teks yang bersifat naratif. Dengan mendisplay data, maka akan memudahkan untuk memahami apa yang terjadi, merencsantrian kerja selanjutnya berdasarkan apa yang telah difahami tersebut. ${ }^{9}$

3. Kesimpulan dan Verifikasi

Langkah selanjutnya menurut Miles and Huberman yaitu penarikan kesimpulan dan verifikasi. Kesimpulan awal yang dikemukakan masih bersifat sementara, dan akan berubah bila tidak ditemukan bukti-bukti yang kuat yang mendukung pada tahap pengumpulan data berikutnya. Tetapi apabila kesimpulan pada tahap awal, di dukung oleh bukti-bukti yang valid dan konsisten saat peneliti kembali ke lapangan mengumpulkan data, maka kesimpulan yang dikemukakan merupakan kesimpulan yang kredibel.10

\section{PEMBAHASAN}

\section{Pembelajaran SAVI}

Pendekatan dengan meggunakan pendekatan SAVI adalah pembelajaran yang menggabungkan gerakan fisik dengan aktivitas intelektual dan penggunaan semua indera yang dapat berpengaruh besar pada pembelajaran.

Adapun unsur-unsur SAVI yang dipaparkn Dave Meier antara lain:

a. Somatis : belajar dengan bergerak dan berbuat

\footnotetext{
${ }^{9}$ J.Moleong, Lexi. Metodologi Penelitian Kualitatif, h. 33.

${ }^{10}$ Sugiyono, Metode Penelitian Pendidikan (Bandung: ALFABETA cv, 2016), 338,341, 345.
} 


\section{Implementasi Metode Savi Untuk Meningkatkan \\ Motivasi Belajar Siswa Mojoagung Jombang}

b. Auditori : belajar dengan berbicara dan mendengar

c. Visual : belajar dengan mengamati

d. Intelektual : belajar dengan memecahkan masalah

Pembelajaran SAVI adalah pembelajaran yang menekankan bahwa belajar haruslah memanfaatkan semua alat indera yang dimiliki peserta didik. SAVI adalah kependekan dari; somatic gerakan tubuh (hans on, aktivitas visik) cara belajar dengan mengalami dan melakukan, auditory yang bermakna belajar haruslah dengan melalui mendengarkan, menyimak, berbicara, presentasi, argumentasi, menanggapi. Visual yang bermakna belajar harusl menggunakan indera mata melalui mengamati, menggambarkan, mendemonstrasikan, membaca, menggunakan media dan alat peraga. Dan intelectual yang bermakna belajar haruslah menggunakan kemampuan berfikir (minds on), belajar haruslah dengan konsentrasi pikiran berlatih menggunakan melalui bernalar, menyelidiki, mengidentifikasi, menemukan, mencipta, mengontruksi, memecahkan masalah, dan menerapkan. ${ }^{11}$

Langkah-langkah dalam menyusun perencanaan pembelajaran SAVI dapat direncanakan dan dikelompokkan dalam empat tahap yaitu: persiapan, penyampaian, pelatihan, dan penampilan hasil. Kreasi apapun guru perlu dengan matang,dalam keempat tahap terebut. ${ }^{12}$

a. Tahap Persiapan (kegiatan pendahuluan)

\footnotetext{
${ }^{11}$ Suyatno, Menjelajah Pembelajaran Inovatif, (Sidoarjo: Masmedia Buana Pustaka, 2009), h. 65.

${ }^{12}$ Ibid.
} 


\section{Ali Muhsin}

Pada tahapan ini guru membangkitkan minat peserta didik,memberikan perasaan positif mengenai pengalaman belajar yang akan datang, dan menempatkan mereka dalam situasi yang optimal untuk belajar. Secara spesifik meliputi hal sebagai berikut:

1) Memberikan sugesti positif

2) Memberikan pernyataan yang memberi manfaat pada peserta didik

3) Memberikan tujuan yang jelas dan bermakna

4) Membangkitkan rasa ingin tahu

5) Menciptakan lingkungan fisik yang positif

6) Menciptakan lingkungan emosional yang positif

7) Menciptakan lingkungan sosial positif

8) Menenangkan rasa takut

9) Menyingkirkan hambatan-hambantan belajar

10) Banyak bertanya dan mengemukakan masalah

11) Merangsang rasa ingin tahu peserta didik

12) Mengajak peserta didik untuk terlibat penuh sejak awal

b. Tahap Penyampaian ( kegiatan inti )

Pada tahap ini peneliti hendaknya membantu siswa menemukan materi belajar yang baru dengan cara melibatkan panca indera, dan cocok untuk semua gaya belajar. Hal-hal yang dapat dilakukan peneliti:

1) Uji coba kolaboratif dan berbagai pengetahuan

2) Pengamatan fenomena dunia nyata

3) Pelibatan seluruh otak, seluruh tubuh

4) Presentasi interaktif

5) Aneka macam cara untuk disesuaikan dengan seluruh gaya belajar

6) Latihan menemukan (sendiri, berpasangan, kelompok) 


\section{Implementasi Metode Savi Untuk Meningkatkan \\ Motivasi Belajar Siswa Mojoagung Jombang}

7) Pengalaman belajar di dunia nyata

8) Pelatihan memecahkan masalah

c. Tahap pelatihan

Pada tahap ini peneliti hendaknya membantu siswa mengintegrasikan dan menyerap pengetahuan dan keterampilan baru dengan berbagai cara. Secara spesifik, yang dilakukan peneliti yaitu:

1) Aktivitas pemprosesan peserta didik

2) Usaha berfikir aktif atau umpan balik atau renungan atau usaha kembali

3) Simulasi dunia nyata

4) Perminan dalam belajar

5) Pelatihan aksi pembelajaran

6) Aktivitas pemecahan masalah

7) Refleksi dan artikulasi individu

8) Dialog berpasangan atau kelompok

9) Pengajaran dan tinjauan kolabortif

10) Aktivitas praktis membangun keterampilan

d. Tahap Penampilan Hasil

Pada tahap ini hendaknya membantu peserta didik menerapkan dan memperluas pengetahuan atau keterampilan baru mereka pada pekerjaan sehingga hasil belajar akan melekat dan penampilan hasil akan terus meningkat. Hal-hal yang dapat dilakukan adalah:

1) Yang mendukung Penerapan dinia nyata dalam waktu yang segera

2) Penciptaan dan pelaksanaan rencana aksi

3) Aktivitas penguatan peesepsi

4) Pelatihan terus menerus 


\section{Ali Muhsin}

5) Umpan balik dan evaluasi kinerja

6) Aktivitas dukungan kawan

7) Perubahan organisasi dan lingkungan

Langkah-langkah metode pembelajaran SAVI ( somatis, auditori, visual, intelektual) antara lain:

a. Siswa membaca materi pelajaran yang akan dipelajari dengan suara keras (A).

b. Siswa dibagi menjadi beberpa kelompok (S).

c. Siswa/setip kelompok mengamati media gambar yang diberikan oleh guru dan mendiskusikannya (V).

d. Setiap kelompok memprsentasikan hasil kerja kelompoknya di depan siswa yang lain sesuai dengan materinya(I).

\section{PENGERTIAN MOTIVASI BELAJAR}

Menurut McClelland dalam The Encyclopedia Dictionary of Psichology yang disusun oleh Hare and Lamb mengungkapkan bahwa motivasi belajar merupakan motivasi berprestasi yang berhubungan dengan pencapaian beberapa standart kepandaian atau standart keahian. ${ }^{13}$ Sementara itu, Heckhausen mengemukakan bahwa motivasi berprestasi adalah suatu dorongan yang terdapat dalam diri siswa yang selalu berusaha atau berjuang untuk meningkatkan atau memelihara kemampuannya setinggi mungkin dalam semua aktivitas dengan menggunakan motivasi standart keunggulan. ${ }^{14}$

\footnotetext{
${ }^{13}$ Dhikrul Hakim, Psikologi Belajar ( Yogyakarta: Erhaka Utama, 2016 ) hal.106

${ }^{14}$ Ibid., hal. 107.
} 


\section{Implementasi Metode Savi Untuk Meningkatkan Motivasi Belajar Siswa Mojoagung Jombang}

Terkait dalam bidang akademik, motivasi berprestasi akan muncul dalam bentuk:

a. Usaha untuk mendapatkan nilai yang baik

b. Dapat mengatasi rintangan belajar

c. Mempertaankan kualitas prestasi belajar yang baik

d. Bersaing dengan orang-orang lain untuk menjadi yang terbaik

Motivasi dapat berfungsi sebgai pendorong usaha dan pencapaian prestasi. Seseorang melakukan suatu usaha karena adanya motivasi. Adanya motivasi yang baik dalam belajar akan menunjukkan hasil yng baik. Dengan kata lain, dengan adanya usaha yang tekun danterutama didasari dengan motivasi,maka seseorang yang belajar itu akan dapat melahirkan prestasi yang baik. Intensitas motivasi seseorang siswa akan sangat menentukan tingkat pencpaian prestasi belajarnya. ${ }^{15}$

Penguatan merupakan peristiwa yang mmpertahhankan atau menemukan bahwa perilaku seseorang dapat dibentuk kurang lebih sama melalui penerapan penguatan positif atau negatif.

\section{HASIL PENELITIAN}

\section{PRA SIKLUS}

Kegiatan pra siklus dilakukan pada tanggal 18 Februari 2019. Beberapa hal yang dilakukan pada kegiatan pra siklus ini antara lain tanya

${ }^{15}$ Dhikrul Hakim, Psikologi Belajar ( Yogyakarta: Erhaka Utama, 2016 ) hal.110 
jawab dengan guru mapel akidah akhlak ibu Irfiana Rohmatin, guru kelas XI IPA dan metode yang digunakan dalam pembelajaran di kelas XI IPA.

Berdasarkan hasil observasi dan wawancara yang dilakukan dengan guru bidang studi Akidah Akhlak di kelas XI IPA MA Assulaimaniyah Mojoagung Jombang sebagai berikut:

a. Irfiana Rohmatin, S.Pd.I, M.Pd. Guru studi akidah akhlak, pada proses pembelajaran berlangsung Guru hanya masih menerapkan metode ceramah, tanya jawab dan metode tugas.

b. Guru belum pernah menerapkan metode SAVI (somatis, auditori, visual intelektual) dikarenakan guru belum pernah mengenal metode tersebut.

c. Motivasi belajar siswa dalam menerima pembelajaran sering merasa bosan,mengantuk dalam mengikuti pelajaran akidah akhlak.

d. Terlihat ada sebagian siswa yang aktif dalam bertanya, tetapi banyak juga siswa yang hanya diam dan mendengarkan ketika pembelajaran sedang berlangsung. ${ }^{16}$

Penyajian data Untuk mengetahui data awal tentang motivasi, peneliti memberikan angket kepada siswa dan tes awal (pre tes) untuk mengetahui pengetahuan awal siswa dalam pelajaran akidah akhlak. Data hasil pengisian angket siswa tentang motivasi siswa sebeum tindakan dapat dilihat pada tabel sebagai berikut:

${ }^{16}$ Irfiana Rohmatin, wawancara, jombang, 11 februari 2019. 


\section{Implementasi Metode Savi Untuk Meningkatkan \\ Motivasi Belajar Siswa Mojoagung Jombang}

\section{Hasil Analisis Angket Motivasi Awal Belajar siswa}

\begin{tabular}{|l|l|c|c|}
\hline No & Indikator & Persentase & Katagori \\
\hline 1 & Tekun menghadapi tugas & $36,87 \%$ & Rendah \\
\hline 2 & Ulet menghadapi kesulitan & $34,60 \%$ & Rendah \\
\hline 3 & Lebih senang bekerja mandiri & $31,52 \%$ & Rendah \\
\hline 4 & $\begin{array}{l}\text { Cepat bosan pada tugas-tugas yang } \\
\text { rutin }\end{array}$ & $31,52 \%$ & Rendah \\
\hline 5 & $\begin{array}{l}\text { Dapat mempertahankan pendapatnya } \\
\text { 6emangat mencari dan memecahkan } \\
\text { masalah soal- soal }\end{array}$ & $34,60 \%$ & Rendah \\
\hline \multicolumn{1}{|c|}{ Rata-rata } & $\mathbf{3 4 , 2 5 \%}$ & Rendah \\
\hline
\end{tabular}

Dari data di atas, dapat diketahui bahwa rata-rata motivasi belajar siswa sebelum dikenai tindakan adalah 34,25 \% dan berada di katagori rendah. Selain hasil angket peneliti juga mendapat hasil pre tes yang dilaksanakan. Data hasil analisis pre tes dapat dilihat pada tabel analisis di bawah ini:

Analisis Nilai Hasil Pre Tes

\begin{tabular}{|c|c|c|c|c|c|}
\hline No & Kategori & Nilai & $\begin{array}{c}\text { Jml. } \\
\text { Siswa }\end{array}$ & Presentase & $\begin{array}{c}\begin{array}{c}\text { Rata- rata } \\
\text { kelas }\end{array} \\
\end{array}$ \\
\hline 1 & Kurang sekali & $<45$ & 10 & $35,71 \%$ & \multirow{6}{*}{$\begin{array}{c}52,14 \% \\
\text { Katagori } \\
\text { kurang }\end{array}$} \\
\hline 2 & Kurang & $45-60$ & 9 & $32,14 \%$ & \\
\hline 3 & Cukup & $61-70$ & 4 & $14,29 \%$ & \\
\hline 4 & Baik & $71-85$ & 5 & $17,86 \%$ & \\
\hline 5 & Sangat baik & $86-100$ & 0 & & \\
\hline & Jumlah & & 28 & $100 \%$ & \\
\hline
\end{tabular}

Berdasarkan tabel di atas, dapat diketahui bahwa rataa-rata kelas hasil pre tes adalah 52,14 \% dan digolongkan dalam katagori kurang. Hanya 17,86 \% siswa aja yang berada dalam katagori baik dan sisanya dalam katagori cukup dan kurang, bahkan 35,71 \% lainnya dalam katagori kurang sekali. Hal 


\section{Ali Muhsin}

ini menunjukkan bahwa prestasi belajar siswa kelas XI IPA masih perlu ditingkatkan.

Kedua tabel di atas, menunjukkan bahwa siswa terdapat hubungan antara motivasi dengan prestasi belajar siswa. Motivasi belajar siswa yang rendah akan mempengaruhi hasil prestasi belajar siswa. Hal inilah yang mendasari peneliti untuk melaksanakan pembelajaran yang dengan metode SAVI guna mengatasi masalah tersebut. Proses pembelajaran yang dilakukan secara lebih nyata akan membantu siswa memahami materi ajar dan dapat mencari solusi atas permaslahan belajar yang dihadapinya.

\section{SIKLUS I}

Siklus 1 diaksanakan dalam satu kali pertemuan pada tanggal 25 Februari 2019 pada jam ke 1-2 dengan alokasi waktu 1 x 45 menit. yang dilaksanakan sesuai dengan jadwal pelajaran akidah akhalak di kelas XI IPA. Materi yang di pelajari pada siklus 1 ini adalah Akhlak terpuji pada pergaulan remaja, kegiatan yang dilaksanakan antara lain sebagai berikut:

a. Peneliti mengucapkan salam, mengkondisikan kelas, berdoa bersama dan memberikan apersepsi.

b. Peneliti menyampaikan materi yang akan dipelajari dengan tujuan mempelajari materi tersebut

c. Peneliti membagi siswa menjadi 3 kelompok

d. Peneliti menginstruksi siswa untuk membuka buku paket

e. Peneliti menyampaikan penjelasan mengenai metode SAVI

f. (somatis, auditoti, visual, intelektual) yang akan dilakukan siswa 


\section{Implementasi Metode Savi Untuk Meningkatkan \\ Motivasi Belajar Siswa Mojoagung Jombang}

g. Peneliti menjelaskan materi yang dibahas (ceramah) dengan slide sebagai contoh dalam materi.

h. Peneliti mengistruksi siswa untuk berdikusi dari materi yang dibahas.

i. Siswa mendiskusikan dengan teman sekelompok sebelum hasil diskusi dan membuat laporan kegiatan SAVI

j. Peneliti beserta siswa membahas hasil diskusi yang diperoleh siswa

k. Siswa mengerjakan soal evaluasi.

1. Peneliti memberi umpan balik berupa nasihat-nasihat

m.Peneliti menutup pelajaran.

Kegiatan observasi dilakukan oleh peneliti sesuai dengan yang telah dilakukan. Secara garis besar, hal-hal yang diamati dalam kegiatan observasi ini antara lain meliputi aktivitas peneliti dan siswa. Hasil analisis observasi pembelajaran menggunakan metode SAVI dan motivasi belajar pada siklus 1 dapat dilihat pada tabel berikut:

Hasil Analisis Angket Motivsi Awal Belajar Siswa

\begin{tabular}{|l|l|l|l|}
\hline No & Indikator & Persentase & Katagori \\
\hline 1 & $\begin{array}{l}\text { Tekun menghadapi } \\
\text { tugas }\end{array}$ & $60,14 \%$ & Sedang \\
\hline 2 & $\begin{array}{l}\text { Ulet menghadapi } \\
\text { kesulitan }\end{array}$ & $54,53 \%$ & Sedang \\
\hline 3 & $\begin{array}{l}\text { Lebih senang bekerja } \\
\text { mandiri }\end{array}$ & $69,59 \%$ & Sedang \\
\hline 4 & $\begin{array}{l}\text { Cepat bosan pada tugas- } \\
\text { tugas yang rutin }\end{array}$ & $51,09 \%$ & Sedang \\
\hline 5 & $\begin{array}{l}\text { Dapat mempertahankan } \\
\text { penda } \\
\text { Patnya }\end{array}$ & $56,88 \%$ & Sedang \\
\hline 6 & $\begin{array}{l}\text { Semangat mencari dan } \\
\text { memecahkan masalah } \\
\text { soal- soal }\end{array}$ & $65,25 \%$ & Sedang \\
\hline \multicolumn{2}{|c|}{ Rata-rata } & $\mathbf{5 7 , 0 8 \%}$ & Sedang \\
\hline
\end{tabular}




\section{Ali Muhsin}

Secara keseluruhan, rata-rata motivasi belajar siswa pda siklus 1 berada pada katagori sedang dengan jumlah 57,08\%. Berikut ini merupakan perbandingan hasil angket motivasi awal belajar dengan hasil angket motivasi belajar siswa siklus 1 .

\section{Perbandingan Hasil Angket Motivasi Belajar Siswa dengan}

Hasil Motivasi Belajar Siswa Sikus 1

\begin{tabular}{|l|l|c|c|}
\hline No & Indikator & $\begin{array}{c}\text { Motivasi } \\
\text { awal }\end{array}$ & $\begin{array}{c}\text { Motivasi } \\
\text { siklus 1 }\end{array}$ \\
\hline 1 & Tekun menghadapi tugas & $36,87 \%$ & $60,14 \%$ \\
\hline 2 & $\begin{array}{l}\text { Ulet menghadapi } \\
\text { kesulitan }\end{array}$ & $34,60 \%$ & $54,53 \%$ \\
\hline 3 & $\begin{array}{l}\text { Lebih senang bekerja } \\
\text { mandiri }\end{array}$ & $31,52 \%$ & $69,59 \%$ \\
\hline 4 & $\begin{array}{l}\text { Cepat bosan pada tugas- } \\
\text { tugas yang rutin }\end{array}$ & $31,52 \%$ & $51,09 \%$ \\
\hline 5 & $\begin{array}{l}\text { Dapat mempertahankan } \\
\text { penda } \\
\text { Patnya }\end{array}$ & $\begin{array}{l}\text { Semangat mencari dan } \\
\text { memecahkan masalah } \\
\text { soal- soal }\end{array}$ & $36,41 \%$ \\
\hline \multicolumn{2}{|l}{ Rata-rata } & $65,25 \%$ \\
\hline 6
\end{tabular}

Dari tabel diatas dapat disimpulkan bahwa motivasi belajar siswa telah mengalami peningkatan dari pra tindakan ke siklus 1 yaitu dari 34,25\% rendah, menjado 57,08 dan berada pada katagori sedang. Selain melalui oservasi dan mnggunakan angket motivasi, peningkatan motivasi belajar siswa juga diamati melalui hasil tes evaluasi belajar. Hasil tes evalusi belajar pada siklus 1 dapat dilihat sebagai berikut: 


\section{Implementasi Metode Savi Untuk Meningkatkan \\ Motivasi Belajar Siswa Mojoagung Jombang}

Hasil Tes Evaluasi Belajar Siswa Siklus 1

\begin{tabular}{|c|c|c|c|c|c|}
\hline No & Kategori & Nilai & $\begin{array}{c}\text { Jml. } \\
\text { Siswa }\end{array}$ & $\begin{array}{c}\text { Prosen } \\
\text { tase }\end{array}$ & $\begin{array}{l}\text { Rata- } \\
\text { rata } \\
\text { kelas }\end{array}$ \\
\hline 1 & $\begin{array}{l}\text { Kurang } \\
\text { sekali }\end{array}$ & $<45$ & 3 & $10,71 \%$ & \multirow{6}{*}{$\begin{array}{c}69,28 \% \\
\text { Katagori } \\
\text { Cukup }\end{array}$} \\
\hline 2 & Kurang & $45-60$ & 10 & $35,7 \%$ & \\
\hline 3 & Cukup & $61-70$ & 2 & $7,14 \%$ & \\
\hline 4 & Baik & $71-85$ & 6 & $21,42 \%$ & \\
\hline 5 & $\begin{array}{l}\text { Sangat } \\
\text { baik }\end{array}$ & $86-100$ & 7 & $24,99 \%$ & \\
\hline & umlah & & 28 & $100 \%$ & \\
\hline
\end{tabular}

Berdasarkan hasil evaluasi diatas, diketahui bahwa rata-rata mencapai $69,28 \%$ dalam katagori cukup. Namu masih terdapat 10,71 \% siswa dalam katagori kurang sekali, dan 35,7 \% dsiswa dalam katagori kurang. Untuk mengetahui hasil evaluasi perbandingan siklus 1 dengan pre tes, dapat dilihat dalam tabel berikut:

Perbandingan Hasil Evaluasi Pre Tes dengan Siklus 1

\begin{tabular}{|c|c|c|c|c|c|c|}
\hline \multirow[b]{2}{*}{ No } & \multirow[b]{2}{*}{ Katagori } & \multirow[b]{2}{*}{ Nilai } & \multicolumn{2}{|c|}{ Pre Tes } & \multicolumn{2}{|c|}{ Siklus 1} \\
\hline & & & $\begin{array}{l}\text { Jml. } \\
\text { Siswa }\end{array}$ & $\%$ & $\begin{array}{c}\text { Jml. } \\
\text { Siswa }\end{array}$ & $\%$ \\
\hline 1 & $\begin{array}{l}\text { Kurang } \\
\text { sekali }\end{array}$ & $<45$ & 10 & $\begin{array}{l}35,71 \\
\%\end{array}$ & 3 & $\begin{array}{l}10,71 \\
\%\end{array}$ \\
\hline 2 & Kurang & $45-60$ & 9 & $\begin{array}{l}32,14 \\
\%\end{array}$ & 10 & $\begin{array}{l}35,7 \\
\%\end{array}$ \\
\hline 3 & Cukup & $61-85$ & 4 & $\begin{array}{l}14,29 \\
\%\end{array}$ & 2 & $\begin{array}{l}7,14 \\
\%\end{array}$ \\
\hline 4 & Baik & $71-85$ & 5 & $\begin{array}{l}17,86 \\
\%\end{array}$ & 6 & $\begin{array}{l}21,42 \\
\%\end{array}$ \\
\hline 5 & $\begin{array}{l}\text { Sangat } \\
\text { baik }\end{array}$ & $86-100$ & 0 & $\begin{array}{l}52,14 \\
\%\end{array}$ & 7 & $\begin{array}{l}24,99 \\
\%\end{array}$ \\
\hline & \multicolumn{2}{|c|}{ Rata-rata } & \multicolumn{2}{|c|}{$15,14 \%$} & \multicolumn{2}{|c|}{$69,28 \%$} \\
\hline
\end{tabular}




\section{Ali Muhsin}

Tabel di atas memperlihtkan bahwa terjasi peningkatan hasil prestasi belajar siswa dari pra tindakan ke siklus 1 sebesar 15,14\% menjadi 69,28\%. Peningkatan tersebut menunjukkan bahwa penggunaan metode SAVI dapat meningkatkan motivasi belajar.

Kekurangan yang Masih Ditemukan dalam Siklus 1 dan Perencanaan yang Akan Dilakukan pada Siklus II

\begin{tabular}{|l|l|l|}
\hline No & Kekurangan & Perencanaan Perbaikan \\
\hline 1 & $\begin{array}{l}\text { Dalam melaksanakan kegiatan } \\
\text { savi, siswa masih kurang mandiri }\end{array}$ & $\begin{array}{l}\text { Memberikan penjelasan yang sejalas- } \\
\text { jelasnya agar siswa tidak bergantung } \\
\text { dengan peneliti }\end{array}$ \\
\hline 2 & $\begin{array}{l}\text { Masih sedikit siswa yang berani } \\
\text { mengemukakan pendapat ketika } \\
\text { berdiskusi }\end{array}$ & $\begin{array}{l}\text { Membimbing siswa agar tercipta suasana } \\
\text { diskusi yang melibatkan semua anggota } \\
\text { kelompok }\end{array}$ \\
\hline 3 & $\begin{array}{l}\text { Antar siswa dan kelompok masih } \\
\text { belum knmak } \\
\text { menyelesaikan kegiatan }\end{array}$ & $\begin{array}{l}\text { Peneliti memberikan pancingan berupa } \\
\text { pertanyaan agar siswa dapat bekerjasama } \\
\text { dengan kelompok }\end{array}$ \\
\hline 4 & $\begin{array}{l}\text { Ada sebagia siswa yang masih } \\
\text { asyik bicara sendiri dengan teman }\end{array}$ & $\begin{array}{l}\text { Mengarahkan dengan baik agar selalu } \\
\text { memperhatikan setiap kegiatan }\end{array}$ \\
\hline 5 & $\begin{array}{l}\text { Kegiatan SAVI masih didominasi } \\
\text { oleh siswa tertentu dalam } \\
\text { kelompoknya }\end{array}$ & $\begin{array}{l}\text { Membentuk kelompok belajar menjadi 5 } \\
\text { kelomppok belajar. Jumlah anggota } \\
\text { kelompok yang sedikit diharapkan akan } \\
\text { membuat siswa lebih aktif tidak bergantung } \\
\text { dengan teman. }\end{array}$ \\
\hline
\end{tabular}

\section{SIKLUS II}

Siklus II diaksanakan dalam satu kali pertemuan pada tanggal 4 Maret 2019 pada jam ke 1-2 dengan alokasi waktu 1 x 45 menit. yang dilaksanakan sesuai dengan jadwal pelajaran akidah akhalak di kelas XI IPA. Materi yang di 


\section{Implementasi Metode Savi Untuk Meningkatkan Motivasi Belajar Siswa Mojoagung Jombang}

pelajari pada siklus 1 ini adalah Akhlak terpuji pada pergaulan remaja, kegiatan yang dilaksanakan antara lain sebagai berikut:

a. Peneliti mengucapkan salam, mengkondisikan kelas, berdoa bersama dan memberikan apersepsi.

b. Peneliti menyampaikan materi yang akan dipelajari dengan tujuan mempelajari materi tersebut

c. Peneliti membagi siswa menjadi 5 kelompok

d. Peneliti menginstruksi siswa untuk membuka buku LKS

e. Peneliti menyampaikan penjelasan mengenai metode SAVI (somatis, auditoti, visual, intelektual) yang akan dilakukan siswa

f. Peneliti mebagi tugas setiap kelompok mendiskusikan sub materi yang ada

g. Siswa mendiskusikan dengan teman sebelum presentasi di depan kelas

h. Siswa presentasikan hasil diskusi dengan simulasi/peran

i. Bagi kelompok yang lain menyimak, bertanya, menyangga kepada kelompok yang presentasi ketika sesi tanya dipersilahkan

j. Peneliti meluruskan dan memberi penguatan jawaban dari masing-masing kelompok yang salah faham

k. Peneliti memberi umpan balik kepada siswa tentang materi yang belum dimengerti

1. Peneliti menutup pelajaran.

Kegiatan observasi dilakukan oleh peneliti sesuai dengan yang telah dilakukan. Secara garis besar, hal-hal yang diamati dalam kegiatan observasi ini antara lain meliputi aktivitas peneliti dan siswa. Hasil analisis observasi pembelajaran menggunakan metode SAVI dan motivasi belajar pada siklus II dapat dilihat pada tabel berikut: 


\section{Ali Muhsin}

\section{Hasil Analisis Angket Motivsi Awal Belajar siklus II}

\begin{tabular}{|l|l|c|c|}
\hline No & Indikator & Persentase & Katagori \\
\hline 1 & Tekun menghadapi tugas & $63,22 \%$ & Tinggi \\
\hline 2 & Ulet menghadapi kesulitan & $63,59 \%$ & Tinggi \\
\hline 3 & Lebih senang bekerja mandiri & $82,07 \%$ & Tinggi \\
\hline 4 & $\begin{array}{l}\text { Cepat bosan pada tugas-tugas } \\
\text { yang rutin }\end{array}$ & $77,17 \%$ & Tinggi \\
\hline 5 & $\begin{array}{l}\text { Dapat mempertahankan penda } \\
\text { Patnya }\end{array}$ & $65,58 \%$ & Tinggi \\
\hline 6 & $\begin{array}{l}\text { Semangat mencari dan } \\
\text { memecahkan masalah soal- soal }\end{array}$ & $58,97 \%$ & Tinggi \\
\hline \multicolumn{2}{|c|}{ Rata-rata } & $\mathbf{6 8 , 4 3 \%}$ & Tinggi \\
\hline
\end{tabular}

Perbandingan Hasil Angket Motivasi Belajar Silus 1

dengan Hasil Motivasi Belajar Siswa Sikus 1I

\begin{tabular}{|l|l|c|c|}
\hline No & Indikator & $\begin{array}{c}\text { Motivasi } \\
\text { sklus 1 }\end{array}$ & $\begin{array}{c}\text { Motivasi } \\
\text { siklus II }\end{array}$ \\
\hline 1 & Tekun menghadapi tugas & $60,14 \%$ & $63,22 \%$ \\
\hline 2 & Ulet menghadapi kesulitan & $54,53 \%$ & $63,59 \%$ \\
\hline 3 & $\begin{array}{l}\text { Lebih senang bekerja } \\
\text { mandiri }\end{array}$ & $69,59 \%$ & $82,07 \%$ \\
\hline 4 & $\begin{array}{l}\text { Cepat bosan pada tugas- } \\
\text { tugas yang rutin }\end{array}$ & $51,09 \%$ & $77,17 \%$ \\
\hline 5 & $\begin{array}{l}\text { Dapat mempertahankan } \\
\text { pendaPatnya }\end{array}$ & $56,88 \%$ & $65,58 \%$ \\
\hline 6 & $\begin{array}{l}\text { Semangat mencari dan } \\
\text { memecahkan masalah } \\
\text { soal- soal }\end{array}$ & $65,25 \%$ & $58,97 \%$ \\
\hline \multicolumn{2}{|c|}{ Rata-rata } & $\mathbf{5 7 , 0 8 \%}$ & $\mathbf{6 8 , 4 3 \%}$ \\
\hline
\end{tabular}

Dari tabel diatas dapat disimpulkan bahwa motivasi belajar siswa telah mengalami peningkatan dari siklus 1 ke siklus II,yaitu dari 57,08 \% sedang, menjadi 68,43 dan berada pada katagori tinggi. Selain melalui oservasi dan 


\section{Implementasi Metode Savi Untuk Meningkatkan \\ Motivasi Belajar Siswa Mojoagung Jombang}

menggunakan angket motivasi, peningkatan motivasi belajar siswa juga diamati melalui hasil tes evaluasi belajar. Hasil tes evalusi belajar pada siklus II dapat dilihat sebagai berikut:

Hasil Tes Evaluasi Belajar Siswa Siklus 1I

\begin{tabular}{|c|c|c|c|c|c|}
\hline No & Kategori & Nilai & $\begin{array}{c}\text { Jml. } \\
\text { Siswa }\end{array}$ & Prosentase & $\begin{array}{c}\text { Rata-rata } \\
\text { kelas }\end{array}$ \\
\hline 1 & Kurang sekali & $<45$ & 0 & $0 \%$ & \multirow{6}{*}{$\begin{array}{c}81,78 \% \\
\text { Katagori } \\
\text { Baik }\end{array}$} \\
\hline 2 & Kurang & $45-60$ & 2 & $35,7 \%$ & \\
\hline 3 & Cukup & $61-70$ & 4 & $7,14 \%$ & \\
\hline 4 & Baik & $71-85$ & 14 & $21,42 \%$ & \\
\hline 5 & Sangat baik & $86-100$ & 8 & $24,99 \%$ & \\
\hline Jumlah & & & 28 & $100 \%$ & \\
\hline
\end{tabular}

Berdasarkan hasil evaluasi diatas, diketahui bahwa rata-rata mencapai $81,78 \%$ dalam katagori baik. Sedangkan perbandingan hasil evaluasi perbandingan siklus 1 dan siklus II dapat dilihat dalam tabel berikut:

Perbandingan Hasil Evaluasi Siklus 1 dengan Siklus 1I

\begin{tabular}{|c|c|c|c|c|c|c|}
\hline \multirow[b]{2}{*}{ No } & \multirow[b]{2}{*}{ Katagori } & \multirow[b]{2}{*}{ Nilai } & \multicolumn{2}{|c|}{ Siklus I } & \multicolumn{2}{|c|}{ Siklus 1I } \\
\hline & & & $\begin{array}{l}\text { Jml. } \\
\text { Siswa }\end{array}$ & $\%$ & $\begin{array}{c}\text { Jml. } \\
\text { Siswa }\end{array}$ & $\%$ \\
\hline 1 & $\begin{array}{l}\begin{array}{l}\text { Kurang } \\
\text { sekali }\end{array} \\
\end{array}$ & $<45$ & 3 & $10,71 \%$ & 0 & $0 \%$ \\
\hline 2 & Kurang & $45-60$ & 10 & $35,7 \%$ & 2 & $\begin{array}{l}35, \\
7 \%\end{array}$ \\
\hline 3 & Cukup & $61-85$ & 2 & $7,14 \%$ & 4 & $\begin{array}{l}7,1 \\
4 \%\end{array}$ \\
\hline 4 & Baik & $71-85$ & 6 & $21,42 \%$ & 14 & $\begin{array}{l}21, \\
42 \\
\%\end{array}$ \\
\hline 5 & $\begin{array}{l}\text { Sangat } \\
\text { baik }\end{array}$ & $86-100$ & 7 & $\begin{array}{l}24,99 \\
\%\end{array}$ & 8 & $\begin{array}{l}24, \\
99 \\
\%\end{array}$ \\
\hline & Rata & & 69,26 & (cukup) & $81,78^{\circ}$ & aik) \\
\hline
\end{tabular}




\section{Ali Muhsin}

Tabel diatas menunjukkanbahwa telah terjdi peningkatan hasil belajar siswa dari siklus I ke siklus II dan meninggkatnya nilai rata-rata kelas, yaitu dari 69,26 \% meningkat menjadi 81,78 \%. Walaupun ada 6 siswa yang nialinya dibawah KKM tetapi 22 siswa di kelas XI IPA ini telah mendapat nilai di atas KKM dengan katagori baik dan sangat baik.

\section{E. KESIMPULAN}

Berdasarkan penelitian dan analisis data yang telah dilakukan dapat disimpulkan bahwa:

1. Metode Pembelajaran di MA Assulaimaniyah sebelum diterapkannya penerapan metode SAVI (somatis, auditori, visual, intelektual) adalah metode konvensional yaitu menggunakan metode ceramah dan tanya jawab

2. Adanya peningkatan motivasi belajar pada Penerapan mote SAVI (somatis,auditori,visual, intelektual) pada pembelajaran akidah akhlak kelas XI IPA MA Assulaimaniyah Mojoagung Jombang dalam katagori baik, dan 75\% siswa mencapai KKM pada ulangan harian..

3. Adanya metode SAVI (somatis, auditori, visual, intelektual) yang digunakan pada pembelajaran akidah akhalak ternyata membuat siswa lebih respek dan ikut berpartisipasi dalam proses pembelajaran. 


\section{Implementasi Metode Savi Untuk Meningkatkan \\ Motivasi Belajar Siswa Mojoagung Jombang}

\section{F. DAFTAR PUSTAKA}

Arikunto Suharsimi. 2010. Prosedur Penelitian Suatu Pendekatan Praktik.Jakarta: PT Rineka Cipta.

A'yuni Qurrota Diyah. 2015. Efektivitas Penerapan Kolaborasi Pendekatan SAVI (Somatic Auditory Visualization Intelektually) Dan Pendektan Talking Stick Terhadap Hasil Belajar Peserta Didik Kelas VII Pada MateriSegiempat Di MTs. NU Hasyim Asy'Ari . Skripsi, UIN Walisongo Semarang.

Fitri, Irsa Ning dkk. "Efektivitas Metode Pembelajaran Snowball Throwing Pada Mata Pelajaran Al-Qur'an Hadist untuk Meningkatkan Minat Belajar Siswa Kelas XI di MAN 1 Jombang", dalam Jurnal At-Tuhfah: Jurnal Studi Keislaman. Vol. 8, No. 2, 2019.

Hakim Dhikrul. 2016. Psikologi Belajar. yogyakarta: Erhaka Utama.

Irfiana Rohmatin, wawancara pada tanggal 11 februari 2019 (wali kelas XI IPA MA Assulaimaniyah Mojoagung Jombang).

Emi Lilawati dan Hidayatur Rohmah. Tanggapan Siswa SMA Kelas X Terhadap Pembelajaran Fiqih Berbasis Murder (Studi kasus di SMA Darul Ulum 1 Unggulan BPPT Jombang), Prosiding Seminar Nasional Multidisiplin, 26 Oktober 2019, Vol 2 No 1, 2019.

Lisa Agustina dan Ghulam Hamdu. 2011, "Pengaruh Motivasi Selajar Siswa Terhadap prestasi Belajar IPA di Sekolah Dasar". Jurnal Penelitian Pendidikan, Vol.12, No. 1.

Mirnawati Binti Lilik. 2017. " Penerapan Model Pembelajaran SAVI untuk Meningkatkan Kemampuan Belajar Mahasiswa PGSD FIKIP Universitas Muhamadiyah Surabaya" jurnal Pendidikan dan Sekolah Dasar. Vol. 1.

J Moleong, Lexi. 2002. Metodologi Penelitian Kualitatif. Bandung: PT Remaja Rosda Karya.c

Nazir Moh.2014. Metode Penelitian . Surabaya: Ghalia Indonesia.

Sugiyono. 2016. Metode Penelitian Pendidikan . Bandung: ALFABETA cv.

Sunyoto Danang. 2013. Metode dan Instrumen Penelitian. Yogyakarta: PT Buku Seru.

Sukardi. 2013. Metode Penelitian Tindakan Kelas . Jakarta: Bumi Aksara

Susilo Joko M. 2006. Gaya Belajar Menjdikan Makin Pintar. Yogyakarta: Pinus. 


\section{Ali Muhsin}

Sumadinata Syaodih Nana. 2016. Metode Penelitian Pendidikan. Bandung: PT Remaja Rosdakarya Offset.

Suyatno. 2009. menjelajah pembelajaran inovatif. Sidoarjo: Masmedia Buana Pustaka.

Suryabrata Sumadi. 2014. Metodologi Penelitian. Jakarta: Rajawali Pers.

Thofuru. 2008. Menjadi Guru Inisiator. Semarang: RaSAIL, Media Group. 